\title{
Advancing age in medicine-bane or boon?
}

\section{Om Prakash Yadava ${ }^{1}$}

Published online: 10 August 2020

(C) Indian Association of Cardiovascular-Thoracic Surgeons 2020

Keywords Cognitive decline $\cdot$ Advancing age $\cdot$ Retirement $\cdot$ Credentialing

Advancing age brings in cognitive decline, which may be of great significance in medicine and becomes all the more relevant for surgical specialities. Yet this seems not to dawn on most of us and we latch on to our chairs more than what is opportune, for 'chair' also brings in its wake money and power. The heady mixture of the latter two corrupt ones sense of fairness, logic and reasoning. In fact it's a rule, rather than an exception, in the private sector, where there is no retirement age, and an individual holds on to his position blocking all avenues for his subordinates. This is one of the important factors for disenchantment of our junior colleagues with our speciality of cardiovascular and thoracic surgery, as the avenues for progress become limited, with each major centre having one 'Bhishm Pitamah', under whose sprawling boughs nothing grows, no seed comes to fruition.

In a debate at the recent Society of Thoracic Surgeons (STS) Conference, answering the conundrum - does age matter-Dr. Robert Guyton from Emory University in Atlanta quipped, 'No contest - of course it does! Physical skills, stamina are weakening, which is balanced by their strongest experiential knowledge base' [1]. Corroborating the latter, Marc Moon, President of American Association of Thoracic Surgery (AATS), Washington University School of Medicine in St Louis stated, 'Surgeon experience has been shown to impact outcomes in select surgical sub-specialities'. He demonstrated that there was a non-linear relationship between patient outcomes after redo cardiac surgery and surgeon experience- 'Learning curve during the first four years; improved outcomes that stabilize mid career, declining outcomes during the most senior years' [2]. Even CCRASS Study had demonstrated that there is $11 \%$ slow speed of visual processing and physical response after the

Om Prakash Yadava

op_yadava@yahoo.com

1 National Heart Institute, New Delhi, India age of 70 years and visual learning and short-term memory begin to fade after the age of 75 years [3]. This study also showed that the measured reaction time too suffers. Providing a counter argument, naysayers contest—advancing age brings in wisdom, and surgeon's experience may prove vital in decision-making and in bailing out of a complex situation.

In this fiercely contested 'pro' and 'con' debate, pithy question is - what is that tipping point, when the cognitive decline of the advancing age becomes a liability and technical skills may begun to vane? Obviously we do not have clear answers, but the Society of Surgical Chairs (SSC) of the American College of Surgeons calling for mandatory screening of cognitive and psycho-motor functions at 65 years of age [4] says it all.

This brings us to the next point, who should bell the cat? Should it be a self-imposed cut off or should it be mandated by a credentialing committee. Can an individual be relied upon for the decision to retire. Dr. Todd Rosengart from Baylor College of Medicine, Houston argued, 'But self-awareness may be lacking and organised counselling and assessment mechanisms should be put into place' [4]. In fact lack of self-awareness has been demonstrated uniformly in most studies and is a recurring theme, which has not been seriously debated and acted upon. The cognitive decline may be gradual and subtle and one may fail to recognise it. And then there is always a prospect that even if one recognises, one may not like to warrant it for fear of financial loss, and even more likely, the loss of power and the attendant hurt of the ego. And yet another reason could be the perceived post-retirement lack of self-worthiness, leading to the loss of self-esteem and the ever lurking fear of being relegated to oblivion in the social fabric of the society.

Coming back on track, the age at which cognitive evaluation should be mandatory can be debated, but some regulations should be in place. It is in the patients' interest foremost, that this should be given due cognisance. A secondary offshoot of it could be that the mid-level cardiac surgeons would get more professional satisfaction and promotional avenues. This would also address one of the causes of lack of interest in 
the speciality, and which incidentally is also a bottle neck for promotion, thereby reducing physician/surgeon burn out.

However, there is a flip side and there may be complaints and litigations on the grounds of age discrimination. This can be effectively attenuated by not unceremoniously discarding or retiring seniors, but to the contrary, re-aligning their work profile. In fact in the intermediary period, medical privileging can change from complex cases to relatively simple cases, as the surgeon tries his hand in alternative fields. They can be gainfully utilised for teaching, mentoring and even operating, but with a competent junior colleague. A team can thus be created of a senior surgeon, using his wisdom and experience and a young surgeon using his better operative skills and dexterity. Senior surgeons can also take non-clinical roles including administration.

Lastly, everyone should put some thoughts into what they would do, when the surgical skills decline. It would behoove all surgeons to plan, mentally and financially, for the ' $\mathrm{D}$ ' day. I am afraid, it's a contentious issue and would ruffle many a feathers, but then is not this high time, right for a healthy debate. I shall keenly look forward to your views and letters.

\section{References}

1. Guyton RA. Performing cardiac surgery - does age matter (pro)? STS Annual Conference 2020. Rosengart TK. Performing cardiac surgery - does age matter? (con) STS Annual Conference 2020.

2. Moon MR. Impact of surgical experience on operative mortality following reoperative cardiac surgery STS Annual Conference 2020.

3. Bieliauskas LA, Langenecker S, Graver C, Lee HJ, O’Neill J, Greenfield LJ. Cognitive changes and retirement among senior surgeons (CCRASS): results from the CCRASS Study. J Am Coll Surg. 2008;207:69-78.

4. Rosengart TK, Doherty G, Higgins R, Kibbe MR, Mosenthal AC. Transition planning for the senior surgeon: Guidance and recommendations from the Society of Surgical Chairs. JAMA Surg. 2019;154: 647-53.

Publisher's note Springer Nature remains neutral with regard to jurisdictional claims in published maps and institutional affiliations. 